A difference in average amount of primary divergence is established between Bantu and European.

The primary divergence enlarges the range of comfortable binocular movement, e.g., in reading.

I would like to acknowledge with gratitude the practical help given me in connection with this work by Professor Raymond A. Dart and Professor J. P. Dalton, of Johannesburg, and by Professor M. R. Drennan of Cape Town.

\title{
REFERENCES
}

1. Stutterheim, N. A.-The Primary Position of the Eyes. Brit.Jl. of Ophihal., July, 1933.

2. Brouwer, B.-Klinisch-anatomische Üntersuchung ueber den Oculomotoriuskern. Zeitschr.f.d. ges. Neurol. Psychiatrie. Bnd. XL, Heft. 1/3, 1918.

3. Stutterheim, N. A. -The Convergence of Human Binocular Vision. Brit. Jl. of Ophthal., January, 1932.

\section{THE USE OF ARTIFICIAL SUNLIGHT FOR ILLUMINATING TEST APPARATUS AND THE GENERAL LIGHTING OF EXAMINATION ROOMS}

BY

LT.-Col. R. E. WRIGHT, C.I.E., I.M.S.

MADRAS

Ophthalmologists in the East are, for the most part, enabled to work in bright rooms, where artificial light is unnecessary for illuminating test types and testing apparatus, or for the naked eye examination of patients. Occasionally where adequate provision for efficient daylight illumination has not been made, artificially lit test types, perimeters, etc., have been used. The disadvantages of such methods did not strike me until in 1931 it became necessary to mount a Bjerrum's screen in an ill-lit room. I then determined to develop the idea of flood lighting and proposed to meet the difficulty of uniform screen illumination by having two suitable lamps mounted in paraboloid reflectors set on stout movable stands with vertical telescopic columns capable of being placed in any position on the floor of the examination room so as to flood the screen with an even light of known intensity. 
Having observed the effect of cinema operator's flood lighting in the darker parts of the hospital, I realized its possibilities for many types of illumination in localities where we were unable to obtain the usual bright daylight. It was not hoped to imitate the clear, sharp daylight obtained from white cloud in a bright sky through a north window which is ideal for most purposes, but rather to reproduce the warmer, softer, yellowish light of direct sunlight. The question of details was postponed until an opportunity should

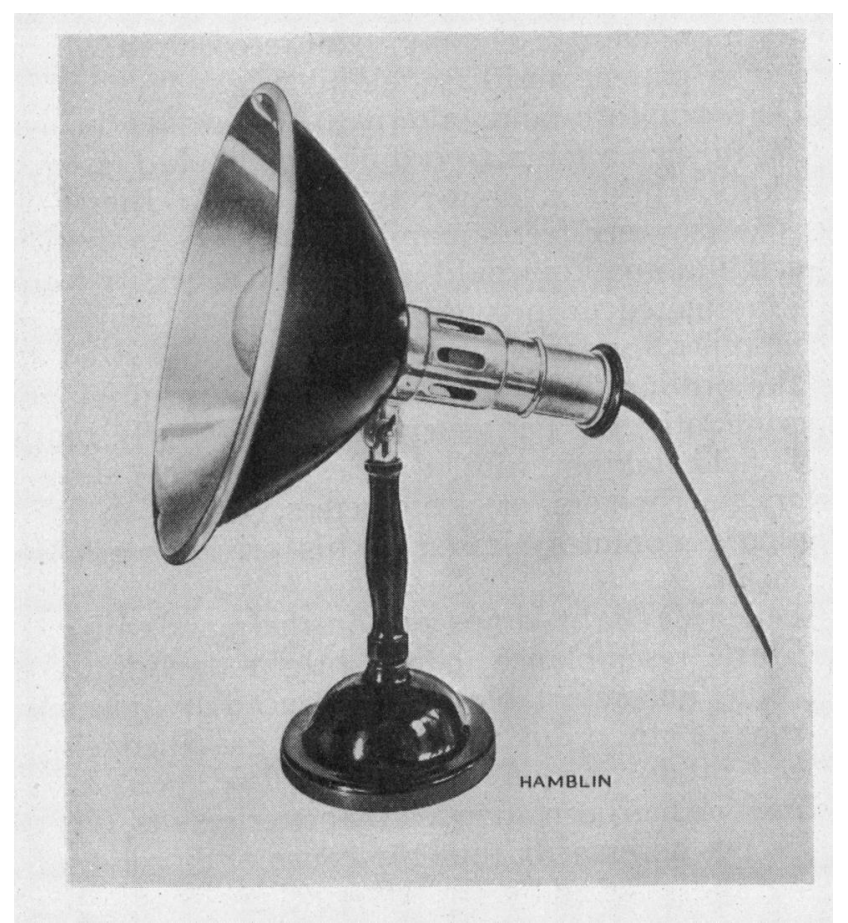

occur of discussing the question with a manufacturing optician in London.

On further consideration of the question in the environment of London during the winter months, it appeared to me that however desirable such a method might be for certain less bright rooms in the East, it was eminently more so under conditions in which the average ophthalmologist works in the British Isles. Apparently conditions such as appertain in the average eye hospital or consulting room in dark western cities have given rise to many of the devices which ophthalmologists and optical instrument manufacturers have developed for illuminating test apparatus. The 
elaborate appartus for presenting test types is often indifferently lighted, difficult of setting up and very expensive. The same is true in connection with the illumination of other test objects. Apart from this altogether, the average illumination of waiting rooms, or the rooms in which patients are subsequently examined, appeared to one accustomed to bright daylight to be inadequate and depressing to patient and doctor, in spite of methods evolved to cope with the darkness and gloom. It seemed that there might be many advantages in having at one's disposal movable lamps of a type which would furnish a good substitute for diffuse sunlight and transform an average gloomy room into one in which general inspection of a patient and case-taking might be conducted with efficiency and comfort, and, alternatively, would be capable of illuminating in such a room an ordinary cardboard test type of any pattern (adults, children, split-ring, etc.) or a Bjerrum's screen of ample size (say six feet square), by a mere movement of the lamps. Such illumination would obviate the necessity for installing specially illuminated drop types and such like, which cater only for Snellen types, and permit the use of a full sized Bjerrum's screen in the ordinary: way even in a small consulting room. By this means quantitative perimetry might ordinarily be performed instead of field taking with the less efficient short distance campimeters, perimeters or scotometers, to which the average ophthalmologist confines himself in his private work for lack of room and light.

The so-called daylight lamps put on the market of recent years have very little resemblance to real bright daylight. Many are of a cold blue uncomfortable tint produced by placing a glass filter in front of an ordinary or special gas-filled electric bulb. The artificial production of the softer yellow, more pleasing tint of direct sunshine has been attended by better results. The tint alone, of course, is not necessarily the only cause of discomfort. A more important one, as stressed by Mr. Affleck Greeves is flicker, e.g., the flicker associated with alternating current. In the course of an enquiry I found a bulb which appeared to be eminently suitable for what I had in view. This is a special gas-filled 240 volt 500 watt Mazda bulb used in the Vita-Rays sun lamp advertised by Messrs. John Bell \& Croyden. A comparison of the spectrum of this lamp and that of summer sunlight shows the close similarity of the properties of these sources of light, the range of rays being almost identical (as tested at the National Physical Laboratory). These gas-filled tungsten filament bulbs require mounting in a reflector with a cooling device. They are expensive-costing about $£ 115 \mathrm{~s}$. - with a life of 300-500 hours. This may be prolonged under certain circumstances. At my suggestion Messrs. Theodore Hamblin, Ltd., arranged to mount such a bulb in a special paraboloid reflector 
on a table lamp-stand so that it can be placed anywhere in a room. When directed upwards in a small room it gives a flood-light from the ceiling efficient and comfortable for general illumination without the source of light catching the eye. When directed at an object, such as a test type, it gives for practical purposes, a parallel beam of calculable illuminating power at known distances.

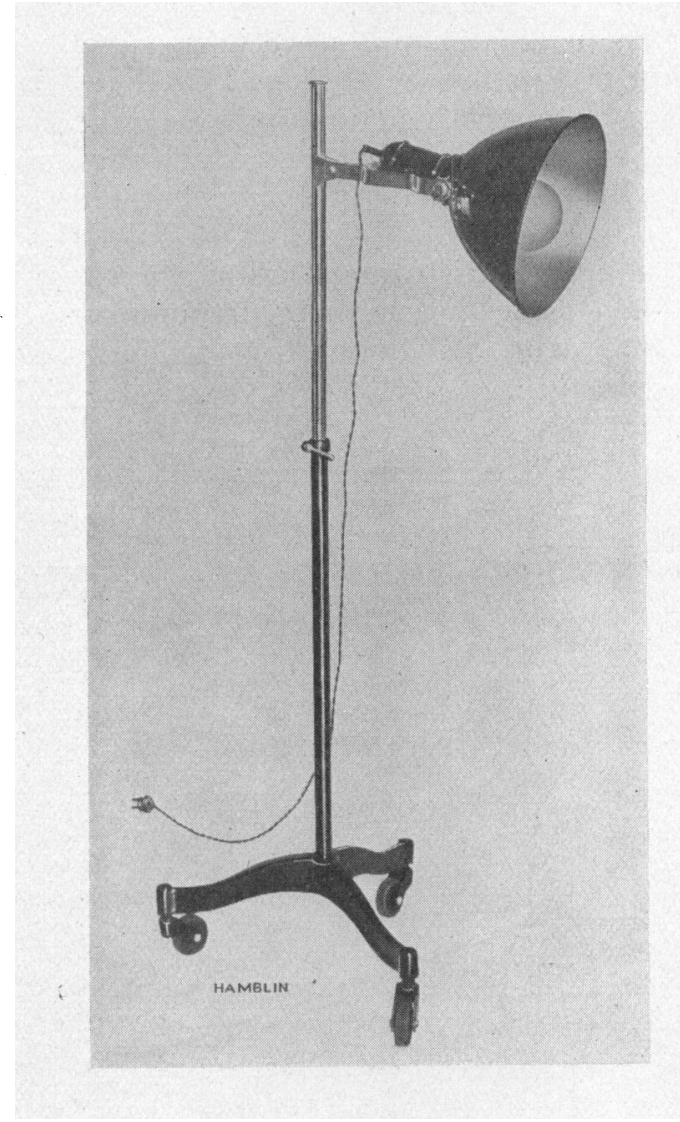

Two such lamps are ideal for screen work when placed on the ground or on small tables behind the patient. Apart from the efficiency of the illumination and ease with which it can be adapted to ordinary desk work, general examination of the patient, or special examination in any part of a big or small room, the comfort of the light for reading and its warmth and the general psychic effect on the patient and doctor are not to be lost sight of. An infra-red unit is obtainable which may be adapted to the reflector instead of the light bulb should it be desirable to use one lamp 
of a pair for heat only. The value of the lamp for purposes of therapeutic irradiation is doubtful, but it will at least give a sun bath qualitatively, if not quantitatively, similar to sun's rays. In this respect it may perhaps be safer than many of the lamps on the market said to provide the more valuable elements of sunshine and a high proportion of ultra-violet rays, the action of which is ill-understood and frequently somewhat startling on the skin and other parts of the anatomy.

These tungsten filament lamps have been suitably adapted for either hospital or private use by Messrs. Theodore Hamblin, Ltd., London, and should be seen in action under average winter weather conditions to be appreciated. The uses which they may subserve, and the list has by no means been exhausted above, may readily be demonstrated. No doubt Messrs. Theodore Hamblin would make suitable modifications to meet individual suggestions. The disadvantages of a somewhat high recurring expenditure should tend to disappear with an increasing demand and improved methods of manufacture.

\section{FOGGING FOR THE FOCAL INTERVAL OF STURM}

BY

\section{Norman GLegG}

WIN DSOR

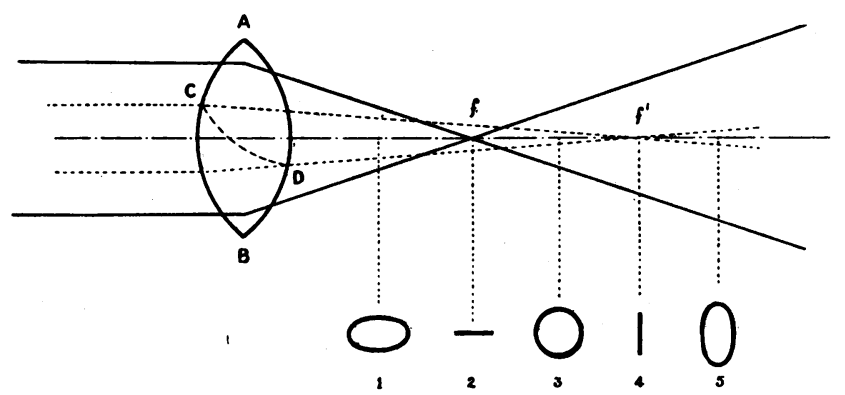

The Focal Interval.

THE following new selective designs in ophthalmic charts provide in a compact and inexpensive form the essentials for analysing refractive errors without a mydriatic. The findings can be suitably modified for the prescription. 